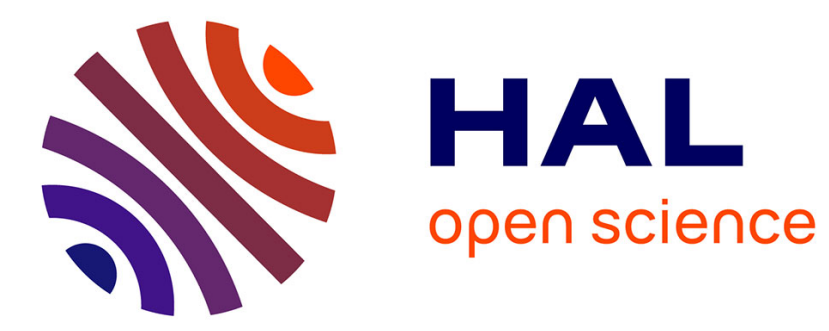

\title{
Susceptibility to ABO and TBOA of LTD and extrasynaptic NMDAR-dependent tonic current in the aged rat hippocampus \\ Patrick Dutar, B Potier
}

\section{- To cite this version:}

Patrick Dutar, B Potier. Susceptibility to ABO and TBOA of LTD and extrasynaptic NMDARdependent tonic current in the aged rat hippocampus. Neurochemical Research, 2019, 44 (3), pp.692702. 10.1007/s11064-018-2677-6 . hal-03318632

\section{HAL Id: hal-03318632 \\ https://hal.science/hal-03318632}

Submitted on 10 Aug 2021

HAL is a multi-disciplinary open access archive for the deposit and dissemination of scientific research documents, whether they are published or not. The documents may come from teaching and research institutions in France or abroad, or from public or private research centers.
L'archive ouverte pluridisciplinaire HAL, est destinée au dépôt et à la diffusion de documents scientifiques de niveau recherche, publiés ou non, émanant des établissements d'enseignement et de recherche français ou étrangers, des laboratoires publics ou privés. 


\section{Susceptibility to Aßo and TBOA of LTD and extrasynaptic NMDAR-dependent tonic current in the aged rat hippocampus.}

\section{Patrick Dutar*, Brigitte Potier*®}

Centre de Psychiatrie et de Neurosciences, INSERM U894, Université Paris-Descartes, 102 rue la Santé, 75014 Paris.

* Present address: Laboratoire Aimé Cotton, CNRS, Univ. Paris-Sud, ENS-Cachan, Université Paris-Saclay, 91405, Orsay, France

Author for correspondence brigitte.potier@u-psud.fr.

亩 : +33 (0)169352140

ORCID number: BP: 0000-0002-9235-7298

PD: 0000-0002-8170-1196

\section{Abstract.}

Aging, as the major risk factor of Alzheimer's disease (AD), may increase susceptibility to neurodegenerative diseases through many gradual molecular and biochemical changes. Extracellular glutamate homeostasis and extrasynaptic glutamate N-Methyl-D-Aspartate receptors (NMDAR) are among early synaptic targets of oligomeric amyloid $\beta(A \beta O)$, one of the $A D$ related synaptotoxic protein species. In this study, we asked for the effects of $A \beta$ o on long-term depression (LTD), a form of synaptic plasticity dependent on extrasynaptic NMDAR activation, and on a tonic current (TC) resulting from the activation of extrasynaptic NMDAR by ambient glutamate in hippocampal slices from young (3-6-month-old) and aged (24-28-month-old) Sprague-Dawley rats. A $\beta$ o significantly enhanced the magnitude of LTD and the amplitude of TC in aged slices compared to young ones. TBOA, a glutamate transporter inhibitor, also significantly increased LTD magnitude and TC amplitude in slices from aged rats, suggesting either an age-related weakness of the glutamate clearance system and/or a facilitated extrasynaptic NMDAR activation. From our present data, we hypothesize that senescence-related impairment of the extrasynaptic environment may be a vector of vulnerability of the aged hippocampus to neurodegenerative promotors such as aßo.

Keywords: Aging, tonic current, extracellular glutamate, synaptic plasticity, NMDA receptors, Alzheimer. 


\section{Introduction.}

A decline in cognition and memory occurs during aging even in the absence of neurodegenerative diseases $[1,2]$, due to gradual changes in the connectivity, structural organization and functional properties in central areas dedicated to learning and memory. One of the most prominent observations is the alterations in synaptic plasticity properties in the different hippocampal synaptic circuits (for review see $[3,4]$ ). Changes in long-term potentiation (LTP), a cellular correlate of learning and memory, are consistently reported to occur during aging, but how long-term depression (LTD) expression is affected by age remains a matter of debate. LTD is implicated in different types of learning and memory and in cognitive flexibility, but more importantly, LTD may underlie synapse silencing and elimination in neurodegenerative diseases [5]. Whereas LTD induction appears to be facilitated in aged rodents (see [6]), other studies point to a weaker ability of hippocampal neuronal networks to express LTD [7-9]. These discrepancies may arise from the diversity of cellular induction mechanisms [5], that can be differentially affected by aging. Among those mechanisms, LTD can be induced by the activation of extrasynaptic NMDAR following glutamate transporters inhibition [10, 11], implicating extracellular glutamate level in synaptic depression. In the hippocampus, $90 \%$ of the extracellular glutamate uptake relies on astrocytes expressing the transporters GLAST and GLT-1 (see [12]). Transporters limit glutamate spill-out to extrasynaptic receptors and spillover to neighboring synapses [13]. Astrocytes are full partners of the synapse, but their neuroprotective properties are also challenged by senescence, playing critical roles in age-related neurological disorders [14]. If changes in glial functions, such as redox homeostasis and inflammatory response, are well known hallmarks of brain aging [15], astrocyte-dependent glutamate uptake has rarely been questioned. Some studies reported a lower uptake and a loss of glutamate transporter sites in the glutamatergic terminals of aged rodents [16-19]. In vivo voltammetric recordings have shown that the loss of GLAST transporters in the striatum of aged Fisher 344 rats was correlated with a slower clearance of glutamate [20]. In previous studies, we consistently described a decrease in GLAST and GLT-1 expression, and a significant reduction in the active glutamate uptake in the hippocampus from different strains of aged rat [21, 22].

Aging is the first risk factor of sporadic Alzheimer's disease (AD). AD is characterized by a progressive decline of cognitive and memory, and by a buildup of extracellular amyloid senile plaques and intra-neuronal neurofibrillary tangles (NFT). The accumulation of amyloid beta $(A \beta)$ protein plays a major role in the pathogenesis of $A D$. The severity of dementia among $A D$ patients better correlates with synaptic loss and oligomeric $A \beta(A \beta O)$ species than with plaque burden $[[23,24]$. Synapse loss is preceded by defects in synaptic transmission and plasticity, and it has been suggested that $A \beta$ o might be involved in the deregulation of these processes [25]. Experimentally, $A \beta$ o has been shown to inhibit LTP, and impairment of synaptic plasticity can be detected in vivo before the formation of insoluble $A \beta$ deposits in $A D$ transgenic mouse models (e.g., $[26,27]$ ). $A \beta$ o originating from different sources has also been shown to facilitate the induction of LTD, when acutely applied to rat organotypic or ex 
vivo hippocampal slices [28], or injected in vivo into the hippocampus [29]. Interestingly, Aßo facilitates the induction of LTD by disrupting astrocyte-dependent glutamate uptake [30, 31] and increasing the activation of extrasynaptic NMDAR [32].

Rare studies have questioned the impact of $A \beta o$ in aged tissue. An in vivo experiment showed that $A \beta$ o injected into the dentate gyrus inhibited LTP in aged but not in young rats suggesting a change in susceptibility due to the underlying age-related neuroinflammation [33]. In the present study, we compared the impact of $A \beta O$ in young and aged hippocampal slices to determine if senescence can be a factor of susceptibility to this neuropathological promotor. We studied the effect of $A \beta O$ on two mechanisms dependent on both extrasynaptic NMDAR activation and extracellular glutamate level, 1) LTD and 2) a tonic current (TC) resulting from extrasynaptic NMDAR activation by ambient glutamate [34]. We observed that $A \beta$ o enhanced the magnitude of LTD in slices from both young and aged rats, but the facilitation of LTD was significantly higher in aged tissue. A 30 also significantly enhanced amplitude of the TC in aged slices compared to young ones. TBOA, a glutamate transporter inhibitor, reproduced the effects of A $B$ o on LTD and TC, and again the magnitude of effect was higher in aged slices. These data suggest that impairment of the extrasynaptic environment (such as an altered glutamate clearance and/or a facilitated extrasynaptic NMDAR activation), could be mechanisms of susceptibility of the aged hippocampal CA1 area to neurodegenerative promotors such as $A \beta$ o.

\section{Material and Methods.}

All animals were treated as approved by the University Paris-Descartes animal care and use committee and experiments were carried out in accordance with the guidelines outlined in the European Communities Council Directive (2010/63/EU). Animals were housed under standard conditions (12 $\mathrm{h}$ day/night rhythm, IVC racks, air-conditioned rooms, standard food, water ad libitum) at the approved animal core facility of INSERM U894 (Paris, France). Twenty-five young (3 - 6-month-old) and 25 aged (24 - 27-month-old) male Sprague-Dawley rats were used in this study, anesthetized by isoflurane before decapitation.

Conventional hippocampal slices were obtained as previously described [35]. Briefly, after removal from the skull, the brain was glued with cyanoacrylate adhesive to a metal block and submerged in the bath of a Leica 1200 S vibroslicer. The artificial CSF (aCSF) bathing solution contained the following (in $\mathrm{mM}$ ): $124 \mathrm{mM} \mathrm{NaCl}, 3.5 \mathrm{mM} \mathrm{KCl}, 1.5 \mathrm{mM}$ $\mathrm{MgSO}_{4}, 2.5 \mathrm{mM} \mathrm{CaCl} 2,26.2 \mathrm{mM}, \mathrm{NaHCO}_{3}, 1.2 \mathrm{mM}, \mathrm{NaH}_{2} \mathrm{PO}_{4}, 11 \mathrm{mM}$, glucose and was maintained at $3^{\circ} \mathrm{C}$. Hippocampal slices were cut in the sagittal plane (400 $\mu \mathrm{m}$ thick) and stored in a recovering chamber in $95 \%$ O2, 5\% CO2 bubbled aCSF at $28^{\circ} \mathrm{C}$. After a $1 \mathrm{~h}$ recovery period, all experiments were performed in bubbled aCSF at room temperature (21 $24^{\circ} \mathrm{C}$ ).

Extracellular recordings were obtained from the CA1 stratum radiatum using glass micropipettes filled with $\mathrm{NaCl} 2 \mathrm{M}$. Field excitatory postsynaptic potentials (fEPSPs) were evoked by electric stimulation of Schaffer collaterals/commissural pathway at $0.1 \mathrm{~Hz}$ with a bipolar tungsten stimulating electrode ( $20 \mu$ s duration). Basal synaptic transmission was 
estimated by averaging the slope of three successive fEPSPs using WinLTP software. The slope was measured between two cursors, one placed as soon after the fiber volley as the fEPSP slope becomes linear, and the second one before it begins to asymptote toward the peak. Long-term depression (LTD) of synaptic transmission was evaluated by a $2 \mathrm{~Hz}$ low frequency stimulation (LFS) paradigm for $10 \mathrm{~min}$. Responses were recorded for at least 45 min after LFS. Drugs were applied in the perfusion bath for at least 15 min before LFS stimulation. Experiments under control conditions were systematically performed on the same day.

Whole-cell patch-clamp recordings of CA1 pyramidal neurons were obtained at room temperature, with borosilicate patch pipettes (open-tip resistance $5 \mathrm{M} \Omega$ ) filled with a solution containing $140 \mathrm{mM} \mathrm{CsCH}{ }_{4} \mathrm{O}_{3} \mathrm{~S}, 6 \mathrm{mM} \mathrm{CsCl}, 2 \mathrm{mM} \mathrm{MgCl}, 10 \mathrm{mM} \mathrm{HEPES}, 1.1 \mathrm{mM}$ EGTA, $5 \mathrm{mM}$ QX-314, and $4 \mathrm{mM}$ ATP, (pH 7.3; 290-310 mosm). Voltage-clamp recordings were performed with an AxoPatch 1-D amplifier (Axon Instruments, Union City, CA). Signals were filtered at $2 \mathrm{~Hz}$ and acquired at a sample rate of $20 \mathrm{kHZ}$ using a National Instruments digitizer and WinLTP software [36]. Access resistance and capacitance were compensated online. Access resistance typically was $10-20 \mathrm{M} \Omega$ and remained relatively stable during experiments.

Experiments assessing tonic NMDAR current were done in the presence of the GABAA receptor (GABAAR) blocker bicuculline methiodide (10 $\mu \mathrm{M}$; Abcam), the $\alpha$-amino-3-hydroxy5-methyl-4-isoxazolepropionic acid receptor (AMPAR) blocker (NBQX; $10 \mu \mathrm{M}$; Ascent Scientific), and the voltage-gated $\mathrm{Na}^{+}$channel blocker tetrodotoxin (TTX; $1 \mu \mathrm{M} ; \mathrm{Abcam}$ ). D-2Amino-5-phosphopentanoic acid (AP-5; $50 \mu \mathrm{M}$; Ascent Scientific) was bath applied to evaluate the NMDA component of the holding current to maintain the recorded neuron at a $+40 \mathrm{mV}$ potential. The amplitude of the tonic current was measured as the difference in the mean holding current values before and after application of AP-5. The change in baseline noise produced by AP- 5 was also assessed. Peak-to-peak amplitude of the baseline noise was measured with Spike 2 software before and after effects of the drugs. Miniature excitatory postsynaptic currents (mEPSCs) were recorded at a holding potential of $-60 \mathrm{mV}$. TTX (1 $\mu \mathrm{M})$ and bicuculline methiodide $(10 \mu \mathrm{M})$ were added to the bath to block action potentials and

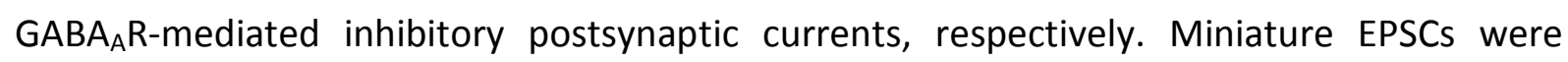
analyzed using the Spike2 program (CED, Cambridge, UK). Peak events were automatically detected using an amplitude threshold of 1.5 times the peak-to-peak baseline noise. Frequency of mEPSCs occurrence was estimated during at least 2 min recording at $-60 \mathrm{mV}$.

Other drugs used in this study include human recombinant $A \beta$ 1-42 (200 nM, Bachem, Weil and Rhein, Germany), and the glutamate transporter inhibitor TBOA (D,L-threo-betabenzyloxyaspartic acid, Tocris, Illkirch, France). Oligomers of amyloid beta protein were prepared as previously described ([32] adapted from [37]). Recombinant A $\beta$ 1-42 peptide was dissolved at $1 \mathrm{mM}$ in 1,1,1,3,3,3-hexafluoro-2-propanolol (HFIP, Sigma, St-Louis, USA) and aliquoted. The HFIP was allowed to evaporate in a fume hood and resulting peptide films were store at $-80^{\circ} \mathrm{C}$. For oligomerization of the peptide, HFIP-treated aliquots were carefully and completely resuspended in $5 \mu \mathrm{l}$ DMSO by pipette mixing, and addition of $108 \mu \mathrm{l}$ of aCSF 
with immediate vortexing. The mixture was then incubated at $4^{\circ} \mathrm{C}$ for $24 \mathrm{~h}$ on a stirring machine. All drugs were diluted directly in aCSF from stock solutions prepared in distilled water or in dimethylsulfoxide (DMSO).

\section{Statistical analysis.}

Two-tailed $t$-tests and paired $t$-tests were used for group comparisons in most cases. Values are means \pm SE. Unless otherwise stated, $n$ was the number of recorded cells in patch-clamp protocols, and slices in extracellular experiments. Statistical tests were performed using StatView Software (SAS Scientific Computing, USA). For analysis of synaptic plasticity, $p$ values were calculated using multivariate analysis of variance followed by Tukey's post hoc tests (StatView software) to account for the correlations inherent to repeated measures in electrophysiological recordings.

\section{Results.}

\section{LTD.}

\section{Effect of $A \beta$ o on LTD.}

The impact of A $A$ o on LTD was first tested. We applied synthetic $A \beta o$ at $200 \mathrm{nM}$, a concentration which is in the pathological range of the hormetic dose-response curve [38], and that we have previously shown to inhibit LTP in the CA1 hippocampus of adult mice [32]. $A \beta o$, perfused for $20 \mathrm{~min}$, comparatively depressed fEPSPs slope during baseline in young and aged slices $(84.6 \pm 2.9 \%$ of the baseline in young, $n=17$ slices from 12 rats, vs $84.2 \pm$ $3.2 \%$ in aged, $n=15$ slices from 12 rats, $n s)$. We first demonstrated that this chemical LTD (CLTD) was stable along time by applying $A \beta$ o for 70 min in aged slices ( $n=7$, data not shown). CLTD induced by $A \beta$ o shares common mechanisms with electrical-induced LTD (eLTD) (see [39]for references), and eLTD could be modified by CLTD-induced metaplastic mechanisms. Consequently, we compared the total LTD (CLTD + eLTD) value between young and aged slices. We showed that total LTD in young animals reached $78.6 \pm 1.7 \%$ in control vs $62.3 \pm$ $9.8 \%$ in $A \beta\left(p=0.04^{*}\right.$ ) (Fig $\left.1 A\right)$. The effect of $A \beta$ o was stronger in aged tissues, reaching 88.5 $\pm 2.2 \%$ in control vs $49.5 \pm 9.6 \%$ in $A \beta 0$. This difference was highly significant $\left(p=0.0001^{* * *}\right)$ (Fig 1B).

\section{Effect of TBOA on LTD.}

We next acutely challenged glutamate uptake by applying the glutamate transporter blocker TBOA. TBOA also induce CLTD of fEPSPs through activation of extrasynaptic NMDAR receptors [10]. When applied at $20 \mu \mathrm{M}$, TBOA induced a significant depression of the fEPSPs slope in hippocampal slices from aged rats $(81.2 \pm 3.8 \%$ of the baseline, $n=10$ slices from 10 aged rats), compared to those of young rats $(94.0 \pm 3.8 \%, n=8$ slices from 8 young rats, $p=$ 0.04; Fig. 2). A control set of experiments was performed to check for the stabilization along 
time of the TBOA-induced cLTD. Stabilization ( $77.5 \pm 7.5 \%$ ( $n=7$ slices in 2 aged rats) was achieved in $20 \mathrm{~min}$, and remained unchanged along a recording period of $70 \mathrm{~min}$ (data not shown). Electrically-evoked LFS was then applied after $20 \mathrm{~min}$ of TBOA perfusion to induce eLTD. We showed that total LTD (cLTD + eLTD) in young animals reached $78.6 \pm 1.7 \%, n=12$ in control vs $56.2 \pm 6.4 \%, n=7$ in TBOA $\left(p=0.0007^{* * *}\right)$ (Fig $\left.2 A\right)$. The effect of TBOA was stronger in aged tissues reaching $88.5 \pm 2.2 \%, n=12$, vs $40.5 \pm 4.7 \%, n=8\left(p<0.0001^{* * *}\right.$ ) (Fig 2B).

\section{Tonic Current.}

The aged hippocampus seems more susceptible to synaptic depression when acutely faced to pathological $A \beta o$ or elevated extracellular glutamate level. We therefore envisaged the age-related alteration in extracellular glutamate homeostasis as a pre-existing vulnerable mechanism in aged tissue. Searching for a more direct evaluation of this alteration, we recorded a tonic current in CA1 pyramidal neurons, mediated by the activation of NMDAR by ambient glutamate. NMDARs are located at both synaptic and extrasynaptic sites, and their activation produces phasic NMDAR current through fast vesicular release and tonic current through action of ambient glutamate, respectively. The tonic activation of NMDAR by ambient glutamate was assessed in whole-cell patch-clamped CA1 pyramidal neurons from young and aged rats, and expressed as a negative shift in the holding current following NMDAR blockade by AP-5 $(50 \mu \mathrm{M})$ from a holding potential of $+40 \mathrm{mV}$. This holding potential allowed for the complete removal of the voltage dependent blockade of NMDARs by external $\mathrm{Mg}^{2+}$ and their possible activation by ambient glutamate. Experiments were performed in the presence of AMPAR, GABA $A$ R, and voltage-gated $\mathrm{Na}^{+}$channel blockers (Fig. $3 A)$. The tonic current amplitude recorded in control conditions was significantly enhanced in neurons from aged rats (205.5 $\pm 11.9 \mathrm{pA}, \mathrm{n}=33$ cells in 25 rats) when compared to neurons from young rats (118.3 $\pm 7.0 \mathrm{pA}, \mathrm{n}=35$ cells in 25 rats, $p<0.001$, Fig. 3B).

The contribution of spontaneous action potential (SAP)-independent release of glutamate can affect measurements of tonic NMDAR current by increasing ambient glutamate concentration, and could participate in the enhancement of TC amplitude in aged rats. The SAP-independent release of glutamate was therefore evaluated in both populations by recording AMPAR-dependent miniature excitatory postsynaptic currents (mEPSCs) at a holding potential of $-60 \mathrm{mV}$. The frequency of mEPSCs occurrence was comparable between young and aged neurons $(0.85 \pm 0.06 \mathrm{~Hz}$ in young, $n=27$ cells in 20 rats, and $1.0 \pm 0.06 \mathrm{~Hz}$ in aged neurons, $n=26$ cells in 23 rats, $p=0.17$ ), as well as the amplitude of the miniature events $(18.6 \pm 1.3 \mathrm{pA}$ in young, $\mathrm{n}=27$ cells in 20 rats, and $20.7 \pm 1.5 \mathrm{pA}$ in aged neurons, $\mathrm{n}=$ 26 cells in 23 rats, $p=0.44$ ), suggesting a comparable sAP-independent vesicular release in young and aged rats (Fig. $4 \mathrm{~A}, \mathrm{~B}$ ).

Tonic NMDAR current was also assessed as the difference in baseline noise before and after NMDAR antagonism. Holding neurons at $+40 \mathrm{mV}$ generates an increase in baseline noise 
amplitude, reflecting the introduction of NMDAR mEPSCs to the baseline current resulting from SAP-independent release (Fig. 5A). As shown in Fig. 5B, peak-to-peak baseline noise amplitude at $+40 \mathrm{mV}$ was comparable in young and aged rats $(52.7 \pm 3.8 \mathrm{pA}$ and $58.5 \pm 2.7$ pA respectively, $p=0.22$ ) before AP-5, and reduced by the drug to $26.9 \pm 2.7 \mathrm{pA}$ in neurons from young ( $n=23$ cells in 19 rats) and $28.2 \pm 1.9$ pA in neurons from aged rats ( $n=22$ cells in 20 rats). When expressed as percent of control, reduction of the baseline noise by AP-5 was comparable in both populations $(51.7 \pm 3.5 \%$ in young versus $48.7 \pm 2.6 \%$ in aged neurons, $p=0.49$, Fig. $5 B$ ). This result, together with the unaffected frequency of glutamate release estimated at $-60 \mathrm{mV}$, is in favor of a comparable contribution of NMDAR mEPSCs input to the tonic current in young and aged rats. We therefore hypothesize that the difference in TC amplitude between young and aged rats may arise mainly from extrasynaptic changes.

TBOA was then applied at $100 \mu \mathrm{M}$ in slices from young and aged rats to inhibit glutamate transporters. TBOA rapidly and reversibly increased the tonic current amplitude (Fig. 6A) in both young and aged rats, as expressed by the positive shift of the holding current at +40 $\mathrm{mV}$. This increase was significantly higher in aged (508.9 $\pm 58.3 \mathrm{pA}, \mathrm{n}=9$ cells in 7 rats) than in young neurons $(232.7 \pm 39.8 \mathrm{pA}, \mathrm{n}=11$ cells in 10 rats, $p=0.001$, Fig. $6 \mathrm{~B}$ and $6 \mathrm{C})$. TBOA also increased the amplitude of the peak-to peak noise compared to baseline (see Fig. 5A). This increase was similar in young (77.9 $\pm 9.9 \mathrm{pA}, \mathrm{n}=11$ in 10 rats) and aged neurons (83.5 \pm 6.3 $\mathrm{pA}, \mathrm{n}=9$ in 7 rats, $\mathrm{p}=0.64)$. These data indicate that the additional NMDA-dependent mEPSCs generated by TBOA was of comparable contribution to the TC in aged and young neurons, and could not account for the difference in TC amplitude.

A $\beta$ o effect was next tested on TC amplitude. When applied at $200 \mathrm{nM}, \mathrm{A} \beta \mathrm{o}$ increased the tonic current amplitude (Fig. 7A) in both young and aged rats, as expressed by the positive shift of the holding current at $+40 \mathrm{mV}$. The increase was significantly higher in aged $(244.0 \pm$ $24.2 \mathrm{pA}, \mathrm{n}=5$ cells in 5 rats) than in young neurons $(96.0 \pm 22.4 \mathrm{pA}, \mathrm{n}=5$ cells in 5 rats, $\mathrm{p}=$ 0.001 , Fig. 7B). A $\mathrm{Bo}$ did not modify the peak-to peak noise (Fig. 7C). Peak-to peak noise quantification was similar in young $(50.4 \pm 10.9 \mathrm{pA}$ in control and $68.8 \pm 13.5 \mathrm{pA}$ in the presence of $A \beta o, n=5$ cells in 5 rats, $p=0.32)$ and aged neurons $(53.6 \pm 10 p A$ in control and $69.2 \pm 13.6 \mathrm{pA}$ in the presence of $A \beta 0, n=5$ cells in 5 rats, $p=0.47$ ), and not significantly different from control baseline noise. This latter result suggests a dominant impact of $A \beta 0$ on the extrasynaptic component of the TC.

\section{Discussion.}

Our present data describe a facilitation effect of acutely applied $A \beta O$ on LFS-induced LTD in aged rat hippocampal slices. The facilitation of LTD by exogenous A $\beta$ o has been widely studied in young animals [30,31,40], and implicate NMDAR and metabotropic glutamate receptor (mGluRs) activation. Synthetic $A \beta$ o peptides have been reported to facilitate LTD induction in an NMDAR dependent manner in vivo [29], and extracted buffer soluble Aßo from AD patients brain facilitated LTD induction in the CA1 region of mouse hippocampus by an mGluR-dependent mechanism [28]. Production of A $\mathrm{Ao}$ in organotypic slices obtained 
from APP-overexpressing mice decreased AMPAR at the cell surface by a mechanism partially occluding LTD [41]. However, all these effects of $A \beta$ o have been demonstrated in young $A D$ mice model tissue or following acute application in young brain tissue, therefore shunting the importance of senescence, the major factor of susceptibility to $A D$. $A \beta$ o has been shown to share some common mechanisms of action with TBOA in adult animals [30], i.e. facilitating LTD by disrupting astrocytic glutamate uptake, and activating extrasynaptic GluN2B-containing NMDAR [31, 42]. In our present experiments, TBOA significantly facilitated LFS-induced LTD in aged slices when compared to young ones, suggesting an extrasynaptic dysregulation in the senescent hippocampus. We then recorded an extrasynaptic NMDAR-dependent TC induced by ambient glutamate in CA1 pyramidal cells, and found that TBOA and $A \beta$ o significantly enhanced TC amplitude in aged slices. Further experiments need to be performed to understand how $A \beta$ o can affect glutamate uptake and extrasynaptic NMDAR and to what extent in the senescent context. Moreover, A $\beta$ o may also act on multiple sites on the GABAergic and cholinergic systems [43] [44], that may indirectly lead to glutamate impairments [45].

Interestingly, we observed a significant increase of the control TC amplitude in aged slices, suggesting an age-associated alteration of the extrasynaptic compartment, which could either arise from an impaired glutamate clearance and/or from a facilitated extrasynaptic NMDAR activation. According to Le Meur et al. [34], the tonic extrasynaptic NMDAR-dependent current in the hippocampus is dependent on glutamate predominantly originating from a non-vesicular origin. This conclusion raised from the inhibition of glutamine synthetase (GS), the astrocytic enzyme responsible for conversion of glutamate to glutamine, which caused an increase in tonic NMDAR current in hippocampal pyramidal neurons. Based on this observation, Le Meur et al. suggested that ambient glutamate was mostly of glial origin. In our experiments, we verified that the spontaneous release of glutamate was unchanged in slices from aged rats, which excluded a higher contribution of the vesicular release to the aged TC. Complementary experiments need to be performed in the presence of bafilomycin (as performed in [46] and [34]), to suppress vesicular glutamate release and to fully isolate the extrasynaptic component of the TC, but we may assume from our present data that the increase in TC amplitude observed in aged rats was more largely due to extracellular glutamate from non-synaptic origin.

During aging, glial cells and particularly astrocytes, are subjected to reactive gliosis $[47,48]$ (see [14] for a review), characterized by a build-up in Glial Fibrillary Acid Protein (GFAP). In a previous study [21], we have described an increase in GFAP in the hippocampal CA1 area of aged rats, using western-blot analysis. With the same method, we did not observe any change in GS protein content; however this does not exclude a decrease in enzyme activity that could account for the change in TC amplitude in aged rats. Reactive gliosis affects volume neurotransmission during physiological and pathological states and a reduction in the extracellular space during senescence influences glutamate spill-over [49, 50]. Moreover, we and others [16, 19, 20, 21, 22] reported a reduction in active glutamate uptake, a decrease in astrocyte glutamate transporters expression, and a slower glutamate 
uptake in aged rats. These different age-related modifications of astrocytes may have impacted the extracellular repartition of glutamate and the tonic activation of extrasynaptic NMDAR, which may ultimately account for an enhancement of the tonic current.

In conclusion, our present data suggest that impairments in the extrasynaptic environment during senescence may contribute to alterations in synaptic plasticity and to an increased susceptibility to neuropathological promotors such as $A \beta 0$.

Conflict of Interest: The authors declare that they have no conflict of interest.

Acknowledgements.

This work was supported in part by INSERM. The authors are grateful to the animal caretakers of the CPN.

Figures Legends.

Fig 1. Effect of $A B$ on time course of LTD in slices from young (A) and aged (C) rats.

$A$ - Effect of $A \beta$ on LTD in young rats. LTD is expressed as a percent change in fEPSP slope across time and is induced by a low frequency stimulation (LFS, $2 \mathrm{~Hz}, 10 \mathrm{~min}$ ) applied at t0 (arrow). Black circles represent mean LTD recorded in control slices from young rats. Grey circles represent the mean LTD recorded in slices from young rats in the presence of $A \beta$ (200 $\mathrm{nM}$ ), applied in the superfusing medium 15 min before t0 and maintained throughout the experiment. $A \beta O$ in young rats has no significant effect on LTD.

B- Same experiments in aged rats. Mean LTD in aged control rats is represented in white circles. Superimposed in grey circles is the mean LTD recorded in slices from aged rats in the presence of $A \beta$ (200 nM), applied in the superfusing medium $15 \mathrm{~min}$ before t0 and continuously applied throughout the experiment. Difference between aged control and aged + A 30 was highly significant $(p<0.0001)$.

$C$ - Examples of individual fEPSPs recorded in young and aged slices in $A \beta$ at time points a and $\mathrm{b}$ indicated in $\mathrm{A}$ and $\mathrm{B}$.

Fig 2. Effect of TBOA on time course of LTD in slices from young (A) and aged (B) rats. LTD is expressed as a percent change in fEPSP slope along time.

A- LTD was applied on slices from young rats recorded in control conditions (black squares) or in the presence of TBOA (20 $\mu \mathrm{M}$, grey squares). LTD was induced by a low frequency stimulation (LFS, $2 \mathrm{~Hz}, 10 \mathrm{~min}$ ) applied at to (arrow). TBOA $(20 \mu \mathrm{M})$ was applied in the superfusing medium after a 15 min baseline. Recording was interrupted during LFS so this period of time does not appear on the figure. LFS induces a depression of the fEPSP slope which recovers partially to reach a stable level of depression about $20 \mathrm{~min}$ after stimulation. The level of LTD was stronger in the presence of TBOA $(p<0.01)$. TBOA was applied throughout the experience. 
B - Same experiments in slices from aged rats. We observed a stronger effect of TBOA in aged compared to young slices $(p=0.0002)$. The depression induced by TBOA on AEPSP before LFS was taken into account for the calculation of LTD.

C- Superimposed examples of individual fEPSPs recorded in young and aged slices in the presence of TBOA at time points $a$ and $b$ indicated in $A$ and $B$.

Figure 3. Tonic NMDAR dependent current in CA1 pyramidal neurons from young and aged rats.

A. Examples of the negative shift of the holding current as a result of $50 \mu \mathrm{M}$ AP- 5 application from a holding potential of $+40 \mathrm{mV}$ (dashed line) are shown in a CA1 neuron from a young (black trace), and aged rat (grey trace). Arrows indicate difference in the shift amplitude relative to baseline. B. Summary of tonic NMDAR-dependent current expressed as a shift in holding current during AP-5 application $(50 \mu \mathrm{M})$, recorded in young (black, $n=35$ ) and aged (white, $n=33$ ) CA1 neurons at $a+40 \mathrm{mV}$ holding potential. The AP-5 induced shift was significantly enhanced in neurons from aged rats $(* * * p<0.001)$.

Figure 4. Spontaneous action potential independent (SAP) release of glutamate in young and aged CA1 pyramidal neurons.

A. Examples of miniature excitatory post-synaptic currents (mEPSCs) in CA1 pyramidal cells in slices from young and aged rats. mEPSCs are marked by asterisks. Holding potential was $60 \mathrm{mV}$. B. Pooled mEPSCs frequency and amplitude in young ( $n=27$; black box) and aged ( $\mathrm{n}$ = 26; grey box) neurons.

Figure 5. Amplitude of the holding current (hc) noise at $+40 \mathrm{mV}$ in young and aged CA1 pyramidal neurons.

A. Hc noise in baseline conditions, in the presence of TBOA $(100 \mu \mathrm{M})$ and AP-5 $(50 \mu \mathrm{M})$ in CA1 pyramidal neurons from young (black traces) and aged (grey traces) rats. B. Pooled data of TBOA and AP-5 effect on hc current noise amplitude recorded in neurons from young (left) and aged rats (right). TBOA statistically increased peak-to peak noise in young $\left({ }^{*} p=\right.$ $0.03)$ and in aged (** $p=0.004)$ rats, but no statistical difference was observed between young and aged rats $(p=0.64)$.

Figure 6. Effect of TBOA on the tonic current in CA1 pyramidal neurons from young and aged rats.

A. Representative trace of the increase in tonic current amplitude induced by TBOA. The hc rapidly returned to baseline upon TBOA washed out. B. Typical examples of the positive shift in the holding current as a result of $100 \mu \mathrm{M}$ TBOA application from a holding potential of + $40 \mathrm{mV}$ (dashed line) are shown in a CA1 neuron from a young (black trace), and aged rat (grey trace). Arrows indicate difference in the shift amplitude relative to baseline. C. Positive shift in holding current induced by TBOA $(100 \mu \mathrm{M})$ application, recorded in young (black, $\mathrm{n}=$ 11) and aged (white, $n=8$ ) CA1 neurons at a $+40 \mathrm{mV}$ holding potential. The effect of TBOA on the tonic current was significantly stronger in neurons from aged rats $\left({ }^{* * *} p<0.001\right)$. 
Figure 7. Effect of $A \beta$ o on the tonic current in $C A 1$ pyramidal neurons from young and aged rats.

A. Positive shift in the holding current as a result of $200 \mathrm{nM}$ Aßo application from a holding potential of $+40 \mathrm{mV}$ (dashed line) in a CA1 neuron from a young (black trace), and aged rat (grey trace). Arrows indicate difference in the shift amplitude relative to baseline. $\mathbf{B}$. Quantification of the shift in holding current induced by $A \beta 0(200 \mathrm{nM})$ application, recorded in young (black, $n=5$ ) and aged (white, $n=5$ ) CA1 neurons at a $+40 \mathrm{mV}$ holding potential $(* * p<0.01)$.

\section{References.}

1. Barnes CA (1979) Memory deficits associated with senescence: a neurophysiological and behavioral study in the rat. J Comp Physiol Psychol 93:74-104

2. Barnes CA, McNaughton BL (1985) An age comparison of the rates of acquisition and forgetting of spatial information in relation to long-term enhancement of hippocampal synapses. Behav Neurosci 99:1040-1048

3. Burke SN, Barnes CA (2006) Neural plasticity in the ageing brain. Nat Rev Neurosci 7:30-40

4. Rosenzweig ES, Barnes CA (2003) Impact of aging on hippocampal function: plasticity, network dynamics, and cognition. Prog Neurobiol 69:143-179

5. Collingridge GL, Peineau S, Howland JG, Wang YT (2010) Long-term depression in the CNS. Nat Rev Neurosci 11:459-473

6. Foster TC (2012) Dissecting the age-related decline on spatial learning and memory tasks in rodent models: $\mathrm{N}$-methyl-D-aspartate receptors and voltage-dependent $\mathrm{Ca} 2+$ channels in senescent synaptic plasticity. Prog Neurobiol 96:283-303

7. Billard JM, Rouaud E (2007) Deficit of NMDA receptor activation in CA1 hippocampal area of aged rats is rescued by D-cycloserine. Eur J Neurosci 25:2260-2268

8. Kollen M, Stephan A, Faivre-Bauman A, Loudes C, Sinet PM, Alliot J, Billard JM, Epelbaum J, Dutar P, Jouvenceau A (2010) Preserved memory capacities in aged Lou/C/Jall rats. Neurobiol Aging 31:129-142

9. Lee HK, Min SS, Gallagher M, Kirkwood A (2005) NMDA receptor-independent long-term depression correlates with successful aging in rats. Nat Neurosci 8:1657-1659

10. Massey PV, Johnson BE, Moult PR, Auberson YP, Brown MW, Molnar E, Collingridge GL, Bashir ZI (2004) Differential roles of NR2A and NR2B-containing NMDA receptors in cortical long-term potentiation and long-term depression. J Neurosci 24:7821-7828

11. Liu DD, Yang Q, Li ST (2013) Activation of extrasynaptic NMDA receptors induces LTD in rat hippocampal CA1 neurons. Brain Res Bull 93:10-16

12. Danbolt NC (2001) Glutamate uptake. Prog Neurobiol 65:1-105

13. Tzingounis AV, Wadiche JI (2007) Glutamate transporters: confining runaway excitation by shaping synaptic transmission. Nat Rev Neurosci 8:935-947

14. Cotrina ML, Nedergaard M (2002) Astrocytes in the aging brain. J Neurosci Res 67:1-10

15. Jiang T, Cadenas E (2014) Astrocytic metabolic and inflammatory changes as a function of age. Aging Cell 13:1059-1067

16. Najlerahim A, Francis PT, Bowen DM (1990) Age-related alteration in excitatory amino acid neurotransmission in rat brain. Neurobiol Aging 11:155-158

17. Saransaari P, Oja SS (1995) Age-related changes in the uptake and release of glutamate and aspartate in the mouse brain. Mech Ageing Dev 81:61-71 
18. Vatassery GT, Lai JC, Smith WE, Quach HT (1998) Aging is associated with a decrease in synaptosomal glutamate uptake and an increase in the susceptibility of synaptosomal vitamin E to oxidative stress. Neurochem Res 23:121-125

19. Wheeler DD, Ondo JG (1986) Time course of the aging of the high affinity L-glutamate transporter in rat cortical synaptosomes. Exp Gerontol 21:159-168

20. Nickell J, Salvatore MF, Pomerleau F, Apparsundaram S, Gerhardt GA (2007) Reduced plasma membrane surface expression of GLAST mediates decreased glutamate regulation in the aged striatum. Neurobiology of Aging 28:1737-1748

21. Potier B, Billard JM, Riviere S, Sinet PM, Denis I, Champeil-Potokar G, Grintal B, Jouvenceau A, Kollen $M$, Dutar $P$ (2010) Reduction in glutamate uptake is associated with extrasynaptic NMDA and metabotropic glutamate receptor activation at the hippocampal CA1 synapse of aged rats. Aging Cell 9:722-735

22. Latour A, Grintal B, Champeil-Potokar G, Hennebelle M, Lavialle M, Dutar P, Potier B, Billard JM, Vancassel S, Denis I (2013) Omega-3 fatty acids deficiency aggravates glutamatergic synapse and astroglial aging in the rat hippocampal CA1. Aging Cell 12:76-84

23. Terry RD, Masliah E, Salmon DP, Butters N, DeTeresa R, Hill R, Hansen LA, Katzman R (1991) Physical basis of cognitive alterations in Alzheimer's disease: synapse loss is the major correlate of cognitive impairment. Ann Neurol 30:572-580

24. McLean CA, Cherny RA, Fraser FW, Fuller SJ, Smith MJ, Beyreuther K, Bush Al, Masters CL (1999) Soluble pool of Abeta amyloid as a determinant of severity of neurodegeneration in Alzheimer's disease. Ann Neurol 46:860-866

25. Selkoe DJ (2002) Deciphering the genesis and fate of amyloid beta-protein yields novel therapies for Alzheimer disease. J Clin Invest 110:1375-1381

26. Hsia AY, Masliah E, McConlogue L, Yu GQ, Tatsuno G, Hu K, Kholodenko D, Malenka RC, Nicoll RA, Mucke L (1999) Plaque-independent disruption of neural circuits in Alzheimer's disease mouse models. Proc Natl Acad Sci U S A 96:3228-3233

27. Mucke L, Masliah E, Yu GQ, Mallory M, Rockenstein EM, Tatsuno G, Hu K, Kholodenko D, Johnson-Wood K, McConlogue L (2000) High-level neuronal expression of abeta 1-42 in wildtype human amyloid protein precursor transgenic mice: synaptotoxicity without plaque formation. J Neurosci 20:4050-4058

28. Shankar GM, Li S, Mehta TH, Garcia-Munoz A, Shepardson NE, Smith I, Brett FM, Farrell MA, Rowan MJ, Lemere CA, Regan CM, Walsh DM, Sabatini BL, Selkoe DJ (2008) Amyloid-beta protein dimers isolated directly from Alzheimer's brains impair synaptic plasticity and memory. Nat Med 14:837-842

29. Kim JH, Anwyl R, Suh YH, Djamgoz MB, Rowan MJ (2001) Use-dependent effects of amyloidogenic fragments of (beta)-amyloid precursor protein on synaptic plasticity in rat hippocampus in vivo. J Neurosci 21:1327-1333

30. Li S, Hong S, Shepardson NE, Walsh DM, Shankar GM, Selkoe D (2009) Soluble oligomers of amyloid Beta protein facilitate hippocampal long-term depression by disrupting neuronal glutamate uptake. Neuron 62:788-801

31. Huang S, Tong H, Lei M, Zhou M, Guo W, Li G, Tang X, Li Z, Mo M, Zhang X, Chen X, Cen L, Wei L, Xiao Y, Li K, Huang Q, Yang X, Liu W, Zhang L, Qu S, Li S, Xu P (2018) Astrocytic glutamatergic transporters are involved in $A \beta$-induced synaptic dysfunction. Brain Research 1678:129-137

32. Kervern M, Angeli A, Nicole O, Leveille F, Parent B, Villette V, Buisson A, Dutar P (2012) Selective impairment of some forms of synaptic plasticity by oligomeric amyloid-beta peptide in the mouse hippocampus: implication of extrasynaptic NMDA receptors. J Alzheimers Dis 32:183-196

33. Minogue AM, Lynch AM, Loane DJ, Herron CE, Lynch MA (2007) Modulation of amyloid-betainduced and age-associated changes in rat hippocampus by eicosapentaenoic acid. J Neurochem 103:914-926 
34. Le Meur K, Galante M, Angulo MC, Audinat E (2007) Tonic activation of NMDA receptors by ambient glutamate of non-synaptic origin in the rat hippocampus. J Physiol 580:373-383

35. Audrain M, Fol R, Dutar P, Potier B, Billard JM, Flament J, Alves S, Burlot MA, DufayetChaffaud G, Bemelmans AP, Valette J, Hantraye P, Deglon N, Cartier N, Braudeau J (2016) Alzheimer's disease-like APP processing in wild-type mice identifies synaptic defects as initial steps of disease progression. Mol Neurodegener 11:016-0070

36. Anderson WW, Collingridge GL (2007) Capabilities of the WinLTP data acquisition program extending beyond basic LTP experimental functions. Journal of Neuroscience Methods 162:346-356

37. Klein WL (2002) A $\beta$ toxicity in Alzheimer's disease: globular oligomers (ADDLs) as new vaccine and drug targets. Neurochemistry International 41:345-352

38. Puzzo D, Privitera L, Palmeri A (2012) Hormetic effect of amyloid-beta peptide in synaptic plasticity and memory. Neurobiology of Aging 33:1484.e1415-1484.e1424

39. Spires-Jones TL, Hyman BT (2014) The intersection of amyloid beta and tau at synapses in Alzheimer's disease. Neuron 82:756-771

40. Takamura Y, Ono K, Matsumoto J, Yamada M, Nishijo H (2014) Effects of the neurotrophic agent T-817MA on oligomeric amyloid-beta-induced deficits in long-term potentiation in the hippocampal CA1 subfield. Neurobiol Aging 35:532-536

41. Hsieh H, Boehm J, Sato C, Iwatsubo T, Tomita T, Sisodia S, Malinow R (2006) AMPAR removal underlies Abeta-induced synaptic depression and dendritic spine loss. Neuron 52:831-843

42. Talantova M, Sanz-Blasco S, Zhang X, Xia P, Akhtar MW, Okamoto S, Dziewczapolski G, Nakamura T, Cao G, Pratt AE, Kang YJ, Tu S, Molokanova E, McKercher SR, Hires SA, Sason H, Stouffer DG, Buczynski MW, Solomon JP, Michael S, Powers ET, Kelly JW, Roberts A, Tong G, Fang-Newmeyer T, Parker J, Holland EA, Zhang D, Nakanishi N, Chen HS, Wolosker H, Wang Y, Parsons LH, Ambasudhan R, Masliah E, Heinemann SF, Pina-Crespo JC, Lipton SA (2013) Abeta induces astrocytic glutamate release, extrasynaptic NMDA receptor activation, and synaptic loss. Proc Natl Acad Sci U S A 110:17

43. Villette V, Dutar P (2017) GABAergic Microcircuits in Alzheimer's Disease Models. Curr Alzheimer Res 14:30-39

44. Zhao LN, Long H, Mu Y, Chew LY (2012) The Toxicity of Amyloid $\beta$ Oligomers. International Journal of Molecular Sciences 13:7303-7327

45. Ondrejcak T, Klyubin I, Hu N-W, Barry AE, Cullen WK, Rowan MJ (2010) Alzheimer's Disease Amyloid $\beta$-Protein and Synaptic Function. NeuroMolecular Medicine 12:13-26

46. Povysheva NV, Johnson JW (2012) Tonic NMDA receptor-mediated current in prefrontal cortical pyramidal cells and fast-spiking interneurons. Journal of Neurophysiology 107:22322243

47. Rozovsky I, Finch CE, Morgan TE (1998) Age-related activation of microglia and astrocytes: in vitro studies show persistent phenotypes of aging, increased proliferation, and resistance to down-regulation. Neurobiol Aging 19:97-103

48. Schipper HM (1996) Astrocytes, brain aging, and neurodegeneration. Neurobiology of Aging 17:467-480

49. Sykova E, Mazel T, Hasenohrl RU, Harvey AR, Simonova Z, Mulders WH, Huston JP (2002) Learning deficits in aged rats related to decrease in extracellular volume and loss of diffusion anisotropy in hippocampus. Hippocampus 12:269-279

50. Sykova E, Vorisek I, Mazel T, Antonova T, Schachner M (2005) Reduced extracellular space in the brain of tenascin-R- and HNK-1-sulphotransferase deficient mice. Eur J Neurosci 22:18731880 